\title{
Elective induction of labour at 39 weeks versus expectant management up to 41 weeks in a tertiary care centre
}

\author{
Yogindra M. Kabadi, Sanjana Kumar*
}

Department of Obstetrics and Gynecology, KIMS, Hubli, Karnataka, India

Received: 14 December 2019

Accepted: 06 January 2020

\section{*Correspondence:}

Dr. Sanjana Kumar,

E-mail: sanjanak60.sk@gmail.com

Copyright: (C) the author(s), publisher and licensee Medip Academy. This is an open-access article distributed under the terms of the Creative Commons Attribution Non-Commercial License, which permits unrestricted non-commercial use, distribution, and reproduction in any medium, provided the original work is properly cited.

\begin{abstract}
Background: The timing of delivery and effective management of labour at term makes a huge difference in the obstetric and perinatal outcome. There have always been controversies between choosing the elective induction of labour at 39 weeks versus expectant management up to $41 / 42$ weeks which can result in placental ageing, reduced liquor, non-assuring fetal heart tracings, meconium stained amniotic fluid and fetal macrosomia. our objective was to perform a comparative effectiveness analysis of elective induction of labor at 39 weeks gestational age among nulliparous women with uncomplicated singleton pregnancies as compared to expectant management up to 41 weeks. Methods: 120 primigravidae with singleton pregnancies with fetus in cephalic presentation were recruited into the study and divided into 2 groups of 60 each A: Patients were induced electively using dinoprostone gel (maximum 3 doses 8 hours apart) B: They were managed expectantly up to 41 weeks allowing for spontaneous onset of labour, induction or cesarean section was done for obstetric indications between 39 and 41 weeks and pregnancy was terminated by induction for those who continued up to 41 weeks. Their obstetric and perinatal outcome were noted.

Results: The cesarean section rates were higher in the expectantly managed group (21\%) when compared to the electively induced group (16\%). The same was with instrumental delivery rates $(15 \%$ versus $10 \%)$. The perinatal outcome was poorer for the expectantly managed group with $20 \%$ NICU admissions and 5\% perinatal deaths compared to the electively induced group which had 12\% NICU admissions and 3.3\% perinatal deaths. The expectantly managed group also resulted in respiratory distress in a larger number of fetuses and resulted in problems due to reduced liquor.

Conclusions: Elective induction at 39 weeks gestational age was found to be a better option compared to expectant management up to 41 weeks in terms of obstetric and perinatal outcomes.
\end{abstract}

Keywords: Elective, Expectant, Induction, Labour, Perinatal outcome, Postdated

\section{INTRODUCTION}

Timing of delivery is a vital component of pregnancy and its outcome. An increase in morbidity and mortality exists on both ends of gestation i.e, preterm and postterm. On one hand, preterm birth is the leading cause of neonatal morbidity and mortality and is associated with substantial healthcare costs. ${ }^{1,2}$ On the other hand, lateterm and post-term pregnancies are also associated with increased maternal, fetal and neonatal risks. ${ }^{3}$ The adjectives post-term, prolonged, postdates, and postmature are often loosely used interchangeably to describe pregnancies that have exceeded a duration considered to be the upper limit of normal. Postmature is reserved for the relatively uncommon specific clinical fetal syndrome in which the infant has recognizable clinical features indicating a pathologically prolonged pregnancy. Perinatal mortality rates increase after the 
expected due date has passed. ${ }^{4}$ While obstetricians generally agree on the management of late and post-term pregnancies, uncertainty exists over the optimal timing of delivery among pregnancies between 39- and 41-week gestation. On one hand, elective induction of labor at 39 weeks gestational age avoids potential risks of ongoing pregnancies including preeclampsia and stillbirth. ${ }^{5}$ Additionally, elective induction decreases the risk of macrosomia with its attendant risk of shoulder dystocia with or without permanent brachial plexus injury, complications due to reduced liquor and meconium stained amniotic fluid, problems due to ageing placenta. Both preeclampsia and fetal macrosomia increase the risk of cesarean delivery. ${ }^{6}$ However, induction of labor also carries risk. Women who undergo induction of labor have higher rates of uterine hyperstimulation and category II and III fetal heart rate tracings. ${ }^{7}$ Additionally, nulliparous patients with an unfavourable cervix undergoing induction of labor may carry a higher rate of cesarean delivery. ${ }^{8}$

This objective was to perform a comparative effectiveness analysis of elective induction of labor at 39 weeks gestational age among nulliparous women with uncomplicated singleton pregnancies as compared to expectant management up to 41 weeks leading to either spontaneous onset of labour or termination of pregnancy by induction or cesarean section due to other obstetric indications.

\section{METHODS}

After taking an informed consent from the study participants, their demographic details were noted. Women with risk factors like PIH, anaemia, hypothyroidism, and other medical disorders were excluded from the study. A detailed history was taken and routine obstetric examination including pelvic assessment was done. A basic obstetric ultrasonography was done to exclude anomalies, note fetal growth parameters and the AFI.

Participants (120) were divided randomly into 2 groups-

- A patient was induced electively using dinoprostone gel (maximum 3 doses 8 hours apart)

- They were managed expectantly up to 41 weeks allowing for spontaneous onset of labour, induction or cesarean section was done for obstetric indications between 39 and 41 weeks and pregnancy was terminated by induction for those who continued up to 41 weeks.

The rates of cesarean section and their indications were noted. The liquor status and cases with meconium stained amniotic fluid were noted. Perinatal outcome was studied based on the birth weights, no of babies developing distress, NICU admissions, early perinatal mortality.

\section{Inclusion criteria}

- All primigravidae with singleton pregnancies who have crossed 39 weeks of gestation admitted at KIMS, Hubli for safe confinement.

\section{Exclusion criteria}

- Women not willing to take part in the study

- Women with medical diseases and other comorbidities/ risk factors affecting obstetric and perinatal outcome

- Women with malpresentations

- Women with contracted pelvis

- Cases with fetal anomalies, fetal growth restriction, reduced or excess liquor requiring urgent intervention

- women already in labour.

\section{Statistical analysis}

Data was tabulated in an excel sheet and analysed using relevant statistical methods like means, percentages, chi square and student t-test, conclusions drawn from the same.

\section{RESULTS}

Among the 120 study participants with each group containing 60 women, about $65 \%$ of them were aged 20 25 years and the 2 groups were comparable based on age (Table 1).

Table 1: Maternal age.

\begin{tabular}{|lllll|}
\hline & $\begin{array}{l}<0 \\
\text { years }\end{array}$ & $\begin{array}{l}\mathbf{2 0 - 2 5} \\
\text { years }\end{array}$ & $\begin{array}{l}\mathbf{2 5 - 3 0} \\
\text { years }\end{array}$ & $\begin{array}{l}>\mathbf{3 0} \\
\text { years }\end{array}$ \\
\hline Group A & 5 & 40 & 12 & 3 \\
\hline Group B & 6 & 18 & 13 & 3 \\
\hline
\end{tabular}

At 39 weeks of gestation, when the subjects were recruited for the study, the average Amniotic fluid index was $10.4 \mathrm{~cm}$ and $11 \mathrm{~cm}$ respectively in group A and group B and the 2 groups were comparable.

Table 2: Average amniotic fluid index.

\begin{tabular}{|lll|}
\hline & At 39 weeks & $\begin{array}{l}\text { On the day of } \\
\text { delivery }\end{array}$ \\
\hline Group A & $10.4 \mathrm{~cm}$ & $10.4 \mathrm{~cm}$ \\
\hline Group B & $11 \mathrm{~cm}$ & $8.2 \mathrm{~cm}$ \\
\hline
\end{tabular}

Group 1 was subjected to induction of labour the same day. Group 2 was managed expectantly up to 41 weeks and induced at 41 weeks. Some of them went into spontaneous labour during this course, were taken for emergency LSCS or induced due to various indications. Their AFI was measured again on the day of delivery and 
the average of group 2 was found to be $8.2 \mathrm{~cm}$ indicating a significant decrease (Table 2).

Among the 60 participants who were in Group B, 26 of them went into spontaneous labour before 41 weeks gestational age of which 21 of them delivered vaginally and 5 were taken for emergency LSCS due to indications like fetal distress and failure to progress. 13/60 were induced for indications like oligoamnios, pre-eclampsia, non-reassuring NST and so on before 41 weeks. 8/13 delivered vaginally and 5 were taken for emergency LSCS. 5/60 women were taken for LSCS before they reached 41 weeks due to indications like utero placental insufficiency, severe oligoamnios and abnormal fetal heart tracings. Only 16/60 participants continued up to 41 weeks and were induced with dinoprostone gel at 41 weeks gestational age of which 10 women delivered vaginally and 6 underwent emergency cesarean section (Figure 1).

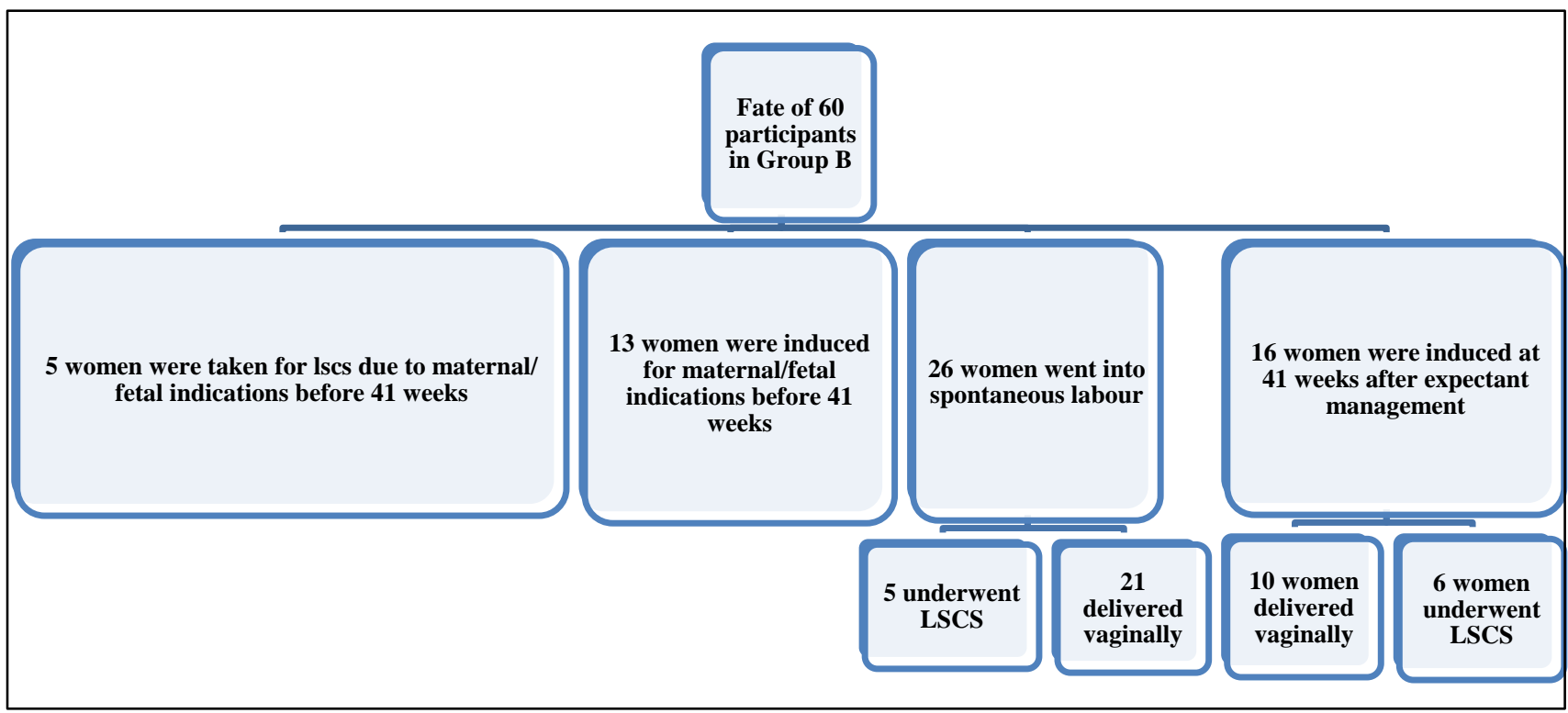

Figure 1: Mode of delivery.

Table 3: Mode of delivery.

\begin{tabular}{|c|c|c|c|c|c|c|}
\hline & $\begin{array}{l}\text { Normal vaginal } \\
\text { delivery }\end{array}$ & $\%$ & Instrumental vaginal delivery & $\%$ & LSCS & $\%$ \\
\hline \multirow{4}{*}{ Group A } & \multirow{4}{*}{38} & \multirow{4}{*}{63.3} & Fetal distress-2 & \multirow{4}{*}{10} & \multirow{4}{*}{16} & \multirow{4}{*}{26.6} \\
\hline & & & Thick msaf-2 & & & \\
\hline & & & Other maternal indications- 2 & & & \\
\hline & & & Total-6 & & & \\
\hline \multirow{4}{*}{ Group B } & \multirow{4}{*}{30} & \multirow{4}{*}{50} & Fetal distress-4 & \multirow{4}{*}{15} & \multirow{4}{*}{21} & \multirow{4}{*}{35} \\
\hline & & & Thick msaf-3 & & & \\
\hline & & & Other maternal indications- 2 & & & \\
\hline & & & Total-9 & & & \\
\hline
\end{tabular}

Table 4: LSCS indications.

\begin{tabular}{|lll|}
\hline LSCS indications & Group a & Group b \\
\hline Fetal distress with/without MSAF, non-reassuring nst & 5 & 8 \\
\hline Thick meconium stained liquor (without FHR variability) & 2 & 3 \\
\hline Oligoamnios & 0 & 3 \\
\hline Failed induction & 4 & 2 \\
\hline Non-progress of labour & 2 & 1 \\
\hline Fetal macrosomia & 0 & 2 \\
\hline Others & 3 & 2 \\
\hline Total & $\mathbf{1 6}$ & $\mathbf{2 1}$ \\
\hline
\end{tabular}


Table 5: Perinatal outcome.

\begin{tabular}{|llllllll|}
\hline & $\begin{array}{l}\text { Avg birth weight } \\
\text { of newborns }\end{array}$ & $\begin{array}{l}\text { Fetal } \\
\text { distress }\end{array}$ & $\%$ & $\begin{array}{l}\text { NICU } \\
\text { admissions }\end{array}$ & $\%$ & $\begin{array}{l}\text { Perinatal } \\
\text { deaths }\end{array}$ & $\%$ \\
\hline Group A & $2.96 \mathrm{~kg}$ & 9 & 15 & 7 & 11.6 & 2 & 3.3 \\
\hline Group B & $3.24 \mathrm{~kg}$ & 15 & 25 & 12 & 20 & 3 & 5 \\
\hline
\end{tabular}

About $63 \%$ of participants from Group A and $50 \%$ of participants from Group B underwent normal vaginal delivery. Instrumental deliveries were found to be higher in Group B (15\%) compared to Group A (10\%) the comonnest indication being fetal distress. Cesarean section rates too were found to be higher in Group B (35\%) in comparison to $27 \%$ in Group A. The results were found to be statistically significant (Table 3 ).

The commonest indication for cesarean section was fetal distress in both the groups, the same being noted in larger numbers in Group B. However, a larger number of women in Group A who were induced electively underwent LSCS due to failed induction in comparison to Group B (Table 4).

The average birth weight was $2.96 \mathrm{~kg}$ in Group A and $3.24 \mathrm{~kg}$ in Group B. About $15 \%$ of babies in Group A and $25 \%$ IN Group B went into distress thus increasing the incidence of instrumental delivery and LSCS. Rates of NICU admissions (7/60 versus 12/60) and perinatal mortality $(3.3 \%$ versus $5 \%)$ too were significantly higher in Group B as compared to Group A. these results were found to be statistically significant (Table 5).

\section{DISCUSSION}

There have always been controversies on choosing between elective induction of labour between 39 and 40 weeks and expectant management to watch for spontaneous onset of labour. It is about outweighing the complications of induction to complications due to post datism. This study aimed to compare the perinatal outcome, LSCS rates between elective induction of labour at 39 weeks versus expectant management up to 41 weeks.

A total 120 primigravidae with singleton pregnancies with fetus in cephalic presentation were recruited into the study and divided into 2 groups of 60 each who were comparable based on their ages and average AFI at the time of recruitment. group A which was subjected to elective induction at 39 weeks had lower rates of instrumental delivery (10\% in Group A versus $15 \%$ in Group B) and cesarean sections (16\% in Group A versus $21 \%$ in Group B) in comparison to Group B wherein the subjects were managed expectantly up to 41 weeks. Most of the sections were indicated due to fetal distress. However, failed induction was also a common indication for LSCS in Group A. These results were similar to the study conducted by William et al wherein the cesarean section rates were $26 \%$ and $29 \%$ respectively in women induced at 39 weeks and women managed expectantly. ${ }^{9}$ In another study conducted by Rachel et al, the cesarean section rates were $14 \%$ and $36 \%$ respectively in the 2 groups. ${ }^{10}$

Fetal perinatal outcome was studied in terms of respiratory distress, NICU admissions and perinatal mortality. Distress was noted in $15 \%$ of Group A and $25 \%$ of Group B. NICU admissions were clearly higher in the expectantly managed group (20\%) as compared to the electively induced group (12\%). Perinatal deaths (still births+ early neonatal deaths) were also higher in Group $\mathrm{B}$ i.e, 3/60 (5\%) compared to group A i.e, 2/60 (3.3\%). This is comparable to the general perinatal mortality rate at KIMS, Hubli which is around 35/1000 live births and perinatal mortality rate in the state of Karnataka which is around 18/1000 live births. In the study conducted by Rachel et al perinatal deaths were $0.12 \%$ and $0.38 \%$ respectively in the 2 groups and the expectantly managed group showed higher perinatal morbidity. ${ }^{10}$ These could be explained due to reduced liquor, placental ageing and higher chances of respiratory distress in post-dated pregnancies making elective induction at 39 weeks a fairer option.

\section{CONCLUSION}

Elective induction at 39 weeks gestational age was found to be a better option compared to expectant management up to 41 weeks in terms of rates of instrumental delivery and LSCS and also perinatal outcome.

Funding: No funding sources Conflict of interest: None declared

Ethical approval: The study was approved by the Institutional Ethics Committee

\section{REFERENCES}

1. Institute of Medicine Committee on Understanding Premature B, Assuring Healthy O. The National Academies Collection: Reports funded by National Institutes of Health In: Behrman RE, Butler AS, editors. Preterm Birth: Causes, Consequences, and Prevention. Washington (DC): National Academies Press (US) National Academy of Sciences; 2007.

2. Practice bulletin no. 130: prediction and prevention of preterm birth. Obstetrics Gynecol. 2012;120(4):964-73. 
3. Practice bulletin no. 146: Management of late-term and postterm pregnancies. Obstet Gynecol. 2014;124(2 Pt 1):390-6.

4. Cunnigham FC, Leveno KJ, Bloom SJ, Hauth JC, Rouse DJ, Spong CY. Williams: obstetrics $24^{\text {th }}$ Edn. United States McGraw-Hill medical publishing division; 2014:973-1000.

5. Hilder L, Costeloe K, Thilaganathan B. Prolonged pregnancy: evaluating gestation-specific risks of fetal and infant mortality. $\mathrm{Br} \mathrm{J}$ Obstet Gynaecol. 1998;105(2):169-73.

6. Caughey AB, Stotland NE, Washington AE, Escobar GJ. Maternal and obstetric complications of pregnancy are associated with increasing gestational age at term. Am J Obstet Gynecol. 2007;196(2):155.e1-6.

7. American College of Obstetricians and Gynecologists. ACOG practice bulletin no. 107: induction of labor. Obstet Gynecol. 2009;114:38697.

8. Luthy DA, Malmgren JA, Zingheim RW. Cesarean delivery after elective induction in nulliparous women: the physician effect. Am J Obstet Gynecol. 2004;191(5):1511-5.

9. Sinkey RG, Lacevic J, Reljic T, Hozo I, Gibson KS, Odibo AO, et al. Elective induction of labor at 39 weeks among nulliparous women: The impact on maternal and neonatal risk. PloS One. 2018;13(4):e0193169.

Cite this article as: Kabadi YM, Kumar S. Elective induction of labour at 39 weeks versus expectant management up to 41 weeks in a tertiary care centre. Int J Reprod Contracept Obstet Gynecol 2020;9:7948. 